\title{
Solitary fibrous tumour of the genitourinary tract: a clinicopathological study of 11 cases and their association with the NAB2-STAT6 fusion gene
}

\author{
Erik Kouba, ${ }_{1}^{1}$ Novae B Simper, ${ }^{1}$ Shaoxiong Chen, ${ }^{1}$ Sean R Williamson, ${ }^{3}$ \\ David J Grignon, ${ }^{1}$ John N Eble, ${ }^{1}$ Gregory T MacLennan, ${ }^{4}$ Rodolfo Montironi, ${ }^{5}$ \\ Antonio Lopez-Beltran, ${ }^{6,7}$ Adeboye 0 Osunkoya, ${ }^{8}$ Shaobo Zhang, ${ }^{1}$ Mingsheng Wang, ${ }^{1}$ \\ Lisha Wang, ${ }^{9}$ Thu Tran, ${ }^{1}$ Robert E Emerson, ${ }^{1}$ Lee Ann Baldrige, ${ }^{1}$ M Francesca Monn, ${ }^{2}$ \\ Konstantinos Linos, ${ }^{10}$ Liang Cheng ${ }^{1,2}$
}

For numbered affiliations see end of article.

\section{Correspondence to} Dr Liang Cheng, Department of Pathology and Laboratory Medicine, Indiana University School of Medicine, 350 West 11 th Street, IUHPL Room 4010, Indianapolis, IN 46202, USA; liang_cheng@yahoo.com

Received 24 August 2016 Revised 3 October 2016 Accepted 8 October 2016

\footnotetext{
To cite: Kouba $\mathrm{E}$, Simper NB, Chen $S$, et al. J Clin Pathol Published Online First: [please include Day Month Year] doi:10.1136/jclinpath-2016204088
}

\begin{abstract}
Aims To characterise clinicopathological features and clinical outcomes of the genitourinary tract solitary fibrous tumours, incorporating NAB2-STAT6 gene fusion status.

Methods The presence of the molecular hallmark NAB2-STAT6 gene fusion and for the defining fusion partner product STAT6 was assessed in 11 cases of the genitourinary tract solitary fibrous tumours. NAB2-STAT6 gene fusion analysis was performed using a break-apart fluorescence in situ hybridisation (FISH) probe using a probe cocktail with Bacterial artificial chromosome (BAC) clones for STAT6 and NAB2.

Results Eleven solitary fibrous tumours were diagnosed in eight male patients and three female patients with a mean age of 46 years (range: 11-64 years). Four of the tumours had malignant histological features, and three were considered moderate risk for metastasis. With a mean follow-up time of 61 months, 1 recurred locally and 2 presented at distant metastatic sites. Using a breakapart FISH probe cocktail, we found the NAB2-STAT6 gene fusion and nuclear STAT6 expression in 58\% and $91 \%$ of cases, respectively. However, the NAB2-STAT6 fusion status was not correlated with STAT6 expression or useful in discriminating between malignant histological features or subsequent clinical outcomes in the genitourinary solitary fibrous tumours.
\end{abstract}

Conclusions A subset of solitary fibrous tumours of the genitourinary tract behaved aggressively. Using a breakapart FISH probe cocktail, we found the NAB2-STAT6 gene fusion in $64 \%$ of cases. However, the NAB2-STAT6 fusion status was not correlated with STAT6 expression or useful in discriminating between low-risk or high-risk tumours and subsequent clinical outcomes.

\section{INTRODUCTION}

Solitary fibrous tumours are rare spindle cell neoplasms-generally arising-from the pleura, but may also involve extrapleural sites including the genitourinary tract. ${ }^{1}$ The clinical course of this tumour is largely indolent; however, aggressive malignant solitary fibrous tumours occur in 15-20\% of cases, presenting in an insidious manner with aggressive behaviour. $^{2}$ The wide spectrum of clinicopathological characteristics and considerable heterogeneity of morphological features found in solitary fibrous tumours can provide both diagnostic and prognostic challenges. ${ }^{3}$ The clinical presentation can be incidental, associated with mass effect symptoms or with the Doege-Potter paraneoplastic syndrome with a presentation related to hypoglycaemia-induced symptoms due to production of an Insulin-like growth factor (IGF) $)_{2}$-like growth factor. ${ }^{4}$

Recently, research has uncovered a recurrent intrachromosomal fusion between the NAB2 and STAT6 genes on chromosome $12 \mathrm{q} 13$ in pleural and extrapleural solitary fibrous tumours. ${ }^{5} 6$ Further investigation revealed strong specificity of the nuclear staining expression using an immunohistochemical antibody for the fusion product (STAT6). With regards to fusion studies, different fusion variants may dominate different locations with potential clinical implications. As such, the biological behaviour of these neoplasms is related to clinicopathological features and may be related to the anatomical site of tumour and the NAB2-STAT6 gene fusion variants. ${ }^{7} 8$ For example, it has been suggested that extrathoracic solitary fibrous tumours behave more aggressively than the pleural counterpart. In fact, recent comparative gene expression profiles between extrapleural and pleural solitary fibrous tumours have demonstrated differences in various discriminatory transcription factor genes with enhancement of cell cycles. ${ }^{9}$ Other studies have examined body site location of solitary fibrous tumours as a prognostic variable and found unclear results when analysed as cohorts at pelvic or abdominal sites. ${ }^{10} 11$ A similar investigation found a statistically significant incidence of tumour progression after surgery between extrathoracic and pleural solitary fibrous tumours, but the magnitude of effect was small. ${ }^{4}$ A similar study of head and neck solitary tumours also reported considerable heterogeneity among locations, histological patterns and NAB2-STAT6 gene fusion variants. ${ }^{12}$

Although these other sites of solitary fibrous tumours have been characterised, no systematic studies incorporating similar comparative variables have evaluated solitary fibrous tumours at the genitourinary tract. These variables include histological features, clinicopathological spectra and the recent hallmark molecular findings. This retrospective study is designed to characterise clinicopathological features and clinical outcomes of the genitourinary tract solitary fibrous tumours. Additionally, we extended the analysis to include

This is the author's manuscript of the article published in final edited form as: 
variables related to the inceptive chromosomal driver including NAB2-STAT6 gene fusion expression using a novel break-apart fluorescence in situ hybridisation (FISH) probe.

\section{METHODS AND MATERIALS}

\section{Patients and tissue selection}

With institutional board review approval, 11 solitary fibrous tumours of the genitourinary tract were identified from the authors' institutional surgical pathology database from the period 2005 to 2014. Representative H\&E-stained slides were reviewed by a senior genitourinary pathologist (LC), and the most histologically representative and best preserved formalin-fixed paraffin-embedded block was chosen for each case with 4-5 $\mu \mathrm{m}$ unstained slides obtained for immunostaining and FISH testing.

Clinicopathological covariates included age at diagnosis, symptomatology, location of tumour, size of tumour, procedure, surgical margin status and invasion of surrounding structures at initial presentation. The outcome variables included progression-free and disease-free survival. Progression was defined as local recurrence (tumour involving tumour bed or scar) or development of metastatic disease at either distant or local sites. ${ }^{13}$

\section{Evaluation of histopathological variables}

Representative H\&E-stained slides along with immunohistochemically stained slides from each case were reviewed by two pathologists independently in a double-blinded fashion. The classical morphological features inherent to this entity were subjectively evaluated for each tumour.

Additional histopathological parameters were evaluated in a quantitative fashion of all available slides of each case to identify features of malignancy and to assign metastatic risk stratification. Tumours were scored for mitotic figures, cellularity, nuclear pleomorphism and presence of necrosis. The absence of necrosis or haemorrhage was defined as minimal. Mitotic index was calculated per 10 high-power fields using the highest count of three to five areas scored. The most cellular area of the tumour was scored for cellularity on a 3-point scale: (1) low (tumour predominately composed of sclerotic collagen bands with scattered, compressed spindle cells), (2) moderate (many areas of increased cellularity with cells adjacent to one another) and (3) high (hypercellular tumour with areas of nuclear overlap). Pleomorphism was scored on a 3-point scale: (1) low (cells monomorphic with uniform nuclear features), (2) moderate (increased nuclear pleomorphism, more prominent nucleoli and rare multinucleated cells) and (3) high (hyperchromatic nuclei present with foci of marked pleomorphism and bizarre cells). Necrosis/haemorrhage was scored as minimal (absence, or $<10 \%)$ or positive $(\geq 10 \%) .^{10}$

The overall risk stratification for the tumour was then calculated using a point system including additional variables of age and tumour size. Points for age: $(<55$ ( 0 point $), \geq 55$ years $(1$ point)); tumour size ( $<5 \mathrm{~cm}$ ( 0 point) $5 \mathrm{~cm}$ to $\geq 10 \mathrm{~cm}$ (1 point), $10 \mathrm{~cm}$ to $<15 \mathrm{~cm}$ ( 2 point) and $\geq 15 \mathrm{~cm}$ ( 3 point)) and mitotic figures (0 (0 point), $1-3$ ( 1 point) and $\geq 4$ ( 2 points)) were as proposed by Demicco et al. ${ }^{10}$ The tumour was assigned a low risk (0-2 total points), moderate risk (3-4 total points) and high risk (5-6 total points).

Cases of solitary fibrous tumours were also categorised as malignant according to the 2013 WHO classification: $>4$ mitotic figures per 10 High power field (HPF) with or without necrosis, hypercellularity, atypia or infiltrative growth patterns. We incorporated a strict definition using the mitotic count as the defining characteristic. ${ }^{14} 15$

\section{Immunohistochemistry}

Two pathologists independently evaluated the stained slides for nuclear STAT6 expression in a blinded manner. The immunohistochemical nuclear expression for STAT6 was quantified using the method presented by Akaike et al: ${ }^{7}$ negative, $<5 \%$ of cells with nuclear staining; focally positive, $5-50 \%$ of cells with nuclear staining; and diffusely positive, $>50 \%$ of cells with nuclear staining. Expression of CD34 (prediluted, clone QBEnd-10, DAKO, Carpinteria, California, USA) and bcl-2 (prediluted, clone 124, DAKO) were also assessed in this fashion. Immunohistochemical staining was performed using the avidin-biotin complex technique, as previously described. Primary rabbit monoclonal antibodies were used for the evaluation of STAT6 expression (1:1000 dilution, clone sc-621, Santa Cruz Biotechnology, Santa Cruz, California, USA). ${ }^{16}$

\section{NAB2-STAT6 fusion gene analysis}

Testing for NAB2-STAT6 fusion by FISH was performed on $4 \mu \mathrm{m}$ sections of the corresponding formalin-fixed, paraffin-embedded tissue. The FISH assays were performed according to a previously described protocol. ${ }^{1718}$ The slides were deparaffinised and treated with 0.1 mmol of citrate buffer ( $\mathrm{pH}$ 6.0) (Zymed, San Francisco, California, USA) at $95^{\circ} \mathrm{C}$ for $10 \mathrm{~min}$. The tissue was then digested with $400 \mu \mathrm{L}$ of pepsin $(5 \mathrm{mg} / \mathrm{mL}$ in $0.01 \mathrm{~N}$ Hydrochloric acid (HCL) with $0.9 \% \mathrm{NaCl}$; Sigma, St Louis, Missouri, USA) at $37^{\circ} \mathrm{C}$ for $40 \mathrm{~min}$ in a humidified chamber. The STAT6 split-apart probe is a cocktail composed of downstream sequence of ATAT6-Green and 146K upstream of STAT6-Orange (Empire genomics, Buffalo, New York, USA). The probes were diluted with tDenHyb2 to a ratio of $1: 25$. The slides were denatured at $80^{\circ} \mathrm{C}$ for $10 \mathrm{~min}$ and hybridised at $37^{\circ} \mathrm{C}$ overnight. The slides were washed twice with $0.1 \times$ Saline-sodium citrate (SSC) $/ 1.5$ moles urea solution at $45^{\circ} \mathrm{C}$ for 20 min each. The slides were then washed with $2 \times$ SSC and $2 \times \mathrm{SSC} / 0.1 \% \mathrm{NP} 40$ each for $10 \mathrm{~min}$ at $45^{\circ} \mathrm{C}$. The slides were counterstained with 4, 6-diamidino-2-phenylindole (DAPI) (Insitus Biotechnologies, Albuquerque, New Mexico, USA). The slides were examined with a Zeiss Axioplan 2 microscope (Ziess, Gottingen, Germany) using the following filters: SP-100 DAPI, MF-101 for Spectrum Green and Gold 31003 for Spectrum Orange (Chroma, Brattleboro, Vermont, USA). The slides were analysed with Isis software (MetaSystem, Belmont, Massachusetts, USA). Four sequential focus stacks with $0.3 \mu \mathrm{m}$ intervals were acquired. The Isis software then integrated the stacks automatically into a single image in order to reduce thickness-related artefacts. Evaluation and analysis of the cases were carried out by two pathologists independently. Between 100 and 200 nonoverlapping cancer cell nuclei were evaluated for each case. Preparations were considered valid if $>90 \%$ of the cells showed bright signals. The inversion fusion of NAB2-STAT6 can generate sequences of $400 \mathrm{~Kb}$ between orange and green probes. Such reversion is manifested by either split-apart orange and yellow signal or deletion of either an orange or a yellow signal with an intact orange-yellow signal pair in a tumour cell (figure 1). A signal pattern showing two closely approximated orange-yellow signals was interpreted as a wild type. Conversely, a separate (split) orange-yellow signal with distance greater than two average signal diameters, or loss of yellow signal was interpreted as a NAB2-STAT6 rearrangement, as illustrated in figure 1 . A NAB2-STAT6 rearrangement was considered positive if $\geq 10 \%$ of analysed cells showed either a split of one set of red-green signals with distance greater than two signal widths and/or if loss of one green signal occurred per Abbott Molecular scoring criteria for Anaplastic lymphoma kinase (ALK). ${ }^{19-21}$ 

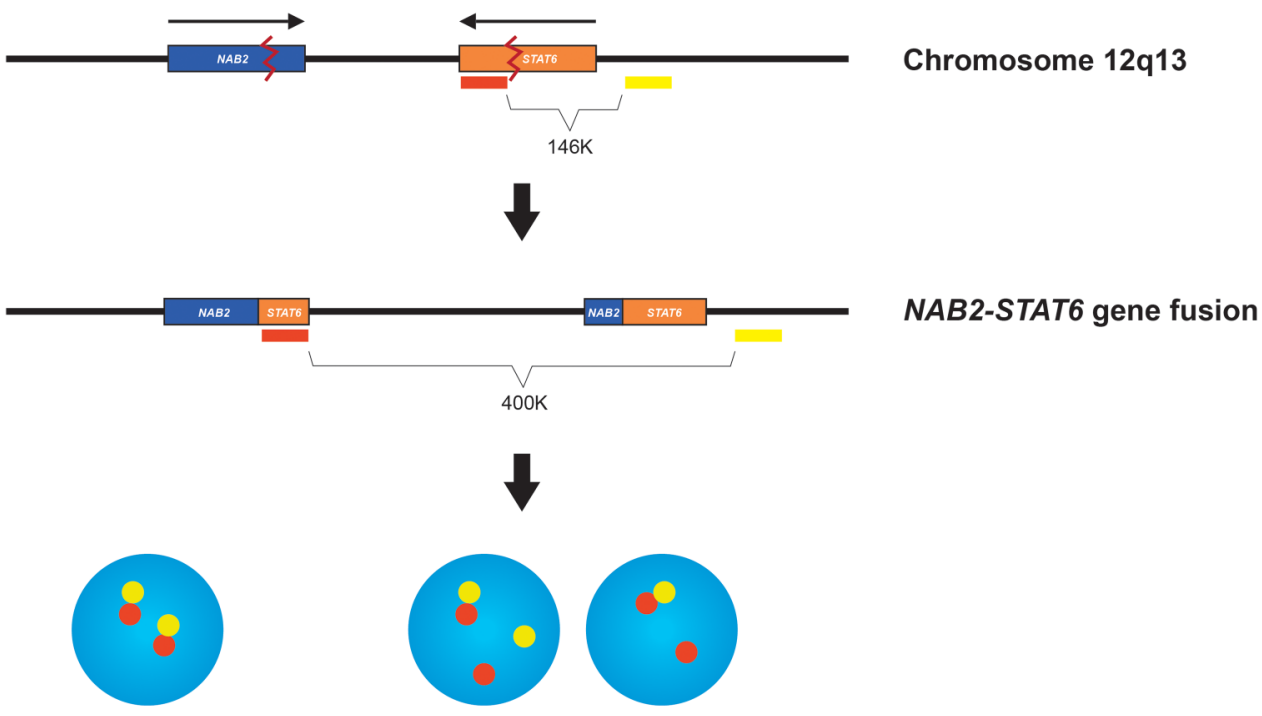

Wild Type

Split apart

Figure 1 Schematic of the STAT6 split-apart fluorescence in situ hybridisation (FISH) probe design. The orange probe recognises the STAT6 $3^{\prime}$ sequence and the yellow probe recognises the STAT6 upstream sequence. The red-yellow probes have a distance of $146 \mathrm{~Kb}$ in the wild type. The NAB2-STAT6 fusion by inversion generates a sequence roughly $400 \mathrm{~Kb}$, which manifested as break-apart orange and yellow signals; or loss of a yellow signal with the presence of intact red-yellow signal pair.

\section{RESULTS}

\section{Clinical characteristics and outcomes}

The study cohort consisted of eight men and three women (table 1). The age at diagnosis ranged from 11 years to 64 years with a mean (median) of $46(50)$ years. The majority of subjects (5 of 7 with available history) presented with symptoms that related to tumour mass effect on adjacent organs leading to abdominal pain, early satiety and irritative voiding symptoms. The patient in case 7 presented with hypoglycaemic symptoms compatible with the solitary fibrous tumour-related Doege-Potter paraneoplastic syndrome.

The locations of the genitourinary solitary fibrous tumours were as follows: kidney $(n=4)$, bladder $(n=3)$, prostate $(n=2)$, adrenal gland $(n=1)$ and testis $(n=1)$. The tumours ranged in size from $2.0 \mathrm{~cm}$ to $9.0 \mathrm{~cm}$ with a mean (median) of $4.7(3.5)$ $\mathrm{cm}$. Four tumours (cases 1, 3, 8 and 10) involved locally adjacent organs at the time of presentation (including liver, soft tissue and vascular structures). The surgical extirpation consisted of wide surgical resection of the organ, tumour and the investing structures. Final surgical margins were negative in cases where assessment was possible. True surgical margins could not be assessed for two bladder solitary fibrous tumours that were removed by transurethral resection instead of partial cystectomy; presumably, complete resection was targeted (table 1).

Clinical progression occurred in three patients at periods of 12-72 months after surgical resection; the mean time to disease progression was 46 months (median, range: 54, 12-72 months, respectively). Progression occurred as loc-regional recurrence in

Table 1 Clinicopathological variables and clinical outcomes of 11 cases of solitary fibrous tumours of the genitourinary tract

\begin{tabular}{|c|c|c|c|c|c|c|c|c|c|}
\hline Case & $\begin{array}{l}\text { Age/gender } \\
\text { (years) }\end{array}$ & Symptoms & Organ & $\begin{array}{l}\text { Tumour size } \\
(\mathrm{cm})\end{array}$ & Margins & $\begin{array}{l}\text { Follow-up } \\
\text { (months) }\end{array}$ & Outcome & $\begin{array}{l}\text { Recurrence } \\
\text { (months) }\end{array}$ & $\begin{array}{l}\text { Metastasis } \\
\text { (months) }\end{array}$ \\
\hline 1 & $59 / \mathrm{M}$ & Weight loss & Kidney & 8.0 & Negative & 56 & DOD & 54 & 54 \\
\hline 2 & $50 / \mathrm{M}$ & No & Kidney & 3.5 & Negative & 22 & NED & $\mathrm{N} / \mathrm{A}$ & $\mathrm{N} / \mathrm{A}$ \\
\hline 3 & $64 / F$ & Unknown & Kidney & 2.8 & Negative & 60 & NED & $\mathrm{N} / \mathrm{A}$ & $\mathrm{N} / \mathrm{A}$ \\
\hline 4 & $29 / F$ & Unknown & Kidney & 2.0 & Negative & LT F/U & $\mathrm{N} / \mathrm{A}$ & $\mathrm{N} / \mathrm{A}$ & $\mathrm{N} / \mathrm{A}$ \\
\hline 5 & $60 / \mathrm{M}$ & No & Prostate & 6.0 & Negative & 81 & NED & $\mathrm{N} / \mathrm{A}$ & $\mathrm{N} / \mathrm{A}$ \\
\hline 6 & $60 / \mathrm{M}$ & $\begin{array}{l}\text { Urinary } \\
\text { obstruction }\end{array}$ & Prostate & 7.0 & Negative & 60 & NED & $\mathrm{N} / \mathrm{A}$ & $\mathrm{N} / \mathrm{A}$ \\
\hline 7 & $33 / \mathrm{F}$ & Hypoglycaemia & Bladder & 3.5 & $\mathrm{~N} / \mathrm{A}$ & 63 & NED & $\mathrm{N} / \mathrm{A}$ & $\mathrm{N} / \mathrm{A}$ \\
\hline 8 & 41/M & $\begin{array}{l}\text { Urinary } \\
\text { obstruction }\end{array}$ & Bladder & 5.7 & Negative & 132 & AWD & 72 & 130 \\
\hline 9 & $11 / \mathrm{M}$ & Unknown & Bladder & 2.2 & $\mathrm{~N} / \mathrm{A}$ & 12 & AWD & 12 & $\mathrm{~N} / \mathrm{A}$ \\
\hline 10 & $58 / \mathrm{M}$ & Abdominal pain & $\begin{array}{l}\text { Adrenal } \\
\text { gland }\end{array}$ & 9.0 & Negative & 60 & $\mathrm{~N} / \mathrm{A}$ & $\mathrm{N} / \mathrm{A}$ & $\mathrm{N} / \mathrm{A}$ \\
\hline 11 & $38 / \mathrm{M}$ & Unknown & Testis & 2.1 & Unknown & LT F/U & $\mathrm{N} / \mathrm{A}$ & $\mathrm{N} / \mathrm{A}$ & $\mathrm{N} / \mathrm{A}$ \\
\hline
\end{tabular}


one patient and metastasis in two patients. Patients with no evidence of disease after resection had a similar mean follow-up period of those who progressed: 58 months (median, range: 60, 22-81 months, respectively; table 1).

The solitary fibrous tumours which progressed after resection tended to have more histological malignant features than those without progression (including $>4$ mitotic figures per $10 \mathrm{HPF}$ and hypercellularity). The patients with disease progression also met criteria for 'moderate metastatic risk' (according to the prognostic model proposed by Demicco et $a l^{10}$ ) (table 2). As aforementioned, this model risk stratifies on tumour size, age and mitotic activity. Excluding case 9, these patients tended to be older, had larger tumours and had more malignant features than those in the 'low metastatic risk' cohort. The histological features associated with aggressive biological behaviour were similar to those reported for extrathoracic solitary fibrous tumours. ${ }^{10}$ Moreover, there was local involvement of surrounding organs in two of three tumours which progressed after resection. Similar relationships between local involvement of surrounding organs and disease recurrence have also been reported in other extrathoracic sites. ${ }^{4}$

\section{Histopathology}

Grossly, the tumours had a white, myxoid-like appearance and were well circumscribed (figure 2A). Histologically, most of the tumours showed typical features of solitary fibrous tumours with alternating hypocellular and hypercellular areas of spindle cells (figure 2B). ${ }^{2}$ Pseudocystic changes were identified in several cases, and small areas of haemorrhage and necrosis were seen in two cases $(<10 \%$ of the area). Case 11 had a prominent myxoid stroma with considerable heterogeneous distribution in degree of cellularity. The majority (7 of $11,64 \%$ ) had high cellularity with clustering cells and minimal intertwined sclerotic collagenous bands. Figure 3 illustrates a renal solitary fibrous tumour with aggressive features (case 1). Quantitative assessment of pleomorphism among tumours was skewed towards moderate and low (high, moderate and low in 18\%, 45\% and 36\%, respectively). ${ }^{10}$ The mitotic rate ranged from 0 to 6 mitotic figures per $10 \mathrm{HPF}$, and only $33 \%$ of tumours displayed mitotic activity (table 2 and figure 3). Haemangiopericytoma-like vessels with thin vascular walls were present in all cases except case 11 which was highly collagenous and partially disrupted secondary to the operative procedure.
All tumours showed positive expression of CD34. The tumours also showed positive expression of bcl-2 in 9 out of 11 cases (table 2).

\section{NAB2-STAT6 gene fusion and STAT6 immunohistochemistry findings}

Seven of 11 tumours (64\%) showed the NAB2-STAT6 fusion using FISH methodology (table 2, figure 2D). There was a relatively uniform and diffuse nuclear expression of STAT 6 in 10 of 11 cases (figure 2C). One case (case 9) did not show nuclear expression; however, FISH test for NAB2-STAT6 fusion gene was positive.

There was no correlation between NAB2-STAT6 gene fusion and malignant histological features of tumours or metastatic risk classification. In addition, there was no correlation between NAB2-STAT6 gene fusion and clinical outcomes, individual genitourinary organs, age or gender. There were no apparent relationships between NAB2-STAT6 gene fusion presence and positive STAT6 nuclear expression in the cohort. In other words, no clinicopathological or histological variable was related to positive nuclear STAT6 expression and absent NAB2-STAT6 gene fusion.

\section{DISCUSSION}

In this retrospective study, the clinicopathological characteristics and disease-related outcomes were examined in a cohort of 11 patients with the genitourinary tract solitary fibrous tumours. The individual organs were represented in the cohort as follows: kidney $(n=4)$, bladder $(n=3)$, prostate $(n=2)$, adrenal gland $(n=1)$ and testis $(n=1)$. To the best of our knowledge, there are no other similar studies that have examined the genitourinary solitary fibrous tumours in a systematic fashion. An understanding of solitary fibrous tumours at this extrapleural site has become increasingly relevant with the discovery of the molecular hallmark NAB2-STAT6 gene fusion. Such genetic aberrations may improve diagnostic and prognostic accuracy and may foster elucidation of additional molecular mechanisms involved in tumorigenesis. ${ }^{2} 131622$

The results of this study show that the individual morphological and immunohistochemical features of the genitourinary solitary fibrous tumours are similar to reported features of other extrathoracic and pleural solitary fibrous tumours. Furthermore, the results demonstrate similar relationships between clinicopathological features and biological behaviour at the different tumour locations. ${ }^{4} 11$ For example, aggressive behaviour of the genitourinary solitary fibrous tumours were related to similar

Table 2 Genetic and histopathological findings of 11 cases of solitary fibrous tumours of the genitourinary tract

\begin{tabular}{|c|c|c|c|c|c|c|c|c|c|}
\hline Case & $\begin{array}{l}\text { NAB2-STAT6 gene } \\
\text { fusion }\end{array}$ & $\begin{array}{l}\text { Nuclear } \\
\text { STAT6 }\end{array}$ & CD34 & $\mathrm{Bcl}-2$ & $\begin{array}{l}\text { Mitotic count } \\
\text { (per } 10 \mathrm{HPF} \text { ) }\end{array}$ & $\begin{array}{l}\text { Cellularity } \\
(1-3)\end{array}$ & $\begin{array}{l}\text { Pleomorphism } \\
(1-3)\end{array}$ & $\begin{array}{l}\text { Malignant } \\
\text { features }\end{array}$ & $\begin{array}{l}\text { Risk* (low, } \\
\text { moderate, high) }\end{array}$ \\
\hline 1 & Positive & Positive & Positive & Positive & 4 & 2 & 2 & Yes & Moderate \\
\hline 2 & Positive & Positive & Positive & Positive & 0 & 3 & 1 & No & Low \\
\hline 3 & Negative & Positive & Positive & Positive & 0 & 3 & 2 & No & Low \\
\hline 4 & Negative & Positive & Positive & Negative & 0 & 3 & 2 & No & Low \\
\hline 5 & Positive & Positive & Positive & Positive & 0 & 3 & 3 & No & Low \\
\hline 6 & Negative & Positive & Positive & Positive & 0 & 1 & 1 & No & Low \\
\hline 7 & Positive & Positive & Positive & Positive & 0 & 2 & 1 & No & Low \\
\hline 8 & Positive & Positive & Positive & Positive & 4 & 3 & 3 & Yes & Moderate \\
\hline 9 & Positive & Negative & Positive & Negative & 6 & 3 & 2 & Yes & Low \\
\hline 10 & Positive & Positive & Positive & Positive & 5 & 3 & 2 & Yes & Moderate \\
\hline 11 & Negative & Positive & Positive & Positive & 0 & 1 & 1 & No & Low \\
\hline
\end{tabular}

${ }^{*}$ Risk: Corresponding to metastatic risk category using methods proposed by Demicco et al..$^{10}$ 
variables as those found at other locations including tumour size $(>10 \mathrm{~cm})$, older age and malignant histological features. In this study, malignant biological behaviour was similar to other body site solitary fibrous tumours (non-actuarial 5-year disease-related progression of $30 \%$ ). Clinical presentation (especially the unique IGF-2 related paraneoplastic syndrome) and gender were also similar to other locations of solitary fibrous tumours. ${ }^{4} 11$

Due to the rarity of the genitourinary solitary fibrous tumours, there are few single institutional series to compare the clinical behaviour and related variables of solitary fibrous tumours of individual genitourinary organs. The comparison must be made with case series comprised of the few published tumours; unfortunately, this method of comparison introduces considerable error related to selection bias, recall bias and absence of complete clinicopathological variables. A single institution study of prostate solitary fibrous tumours identified malignant features but found no recurrence over a follow-up of 1-10 years. ${ }^{23}$ Our cases of prostatic solitary fibrous tumours in this study are similar to published cases/series: large tumours $(6-7 \mathrm{~cm})$, older patients and few malignant histological features. ${ }^{1} 23-25$

A comparison of the four kidney solitary fibrous tumours in our series between a large compilation renal solitary fibrous tumours pooled from the literature $(n=36)$ shows a similarly wide range of tumour sizes, malignant features and a $10-15 \%$ recurrence rate. ${ }^{26}$ An additional study of renal solitary fibrous tumours $(n=46)$ also reported many of the same clinicopathological features found in the cases of this study. ${ }^{27}$ In these published studies, however, variables related to malignant clinical behaviour were histological (mitotic activity, pleomorphism and cellularity). These studies did not examine tumour size, age or local involvement of other structures. Moreover, the NAB2-STAT6 gene fusion presence and STAT6 nuclear expression were not examined. $^{26} 28$ These genetic features may also have implications related to studies of molecular interactions of NAB2 and EGR1 and their involvement in chronic kidney disease and tumorigenesis of solitary fibrous tumours by acquisition of complex genomic profiles. This mechanism of acquisition of oncogenes has been studied in other dedifferentiated solitary fibrous tumours. $^{26}$ 29-31 Ongoing studies examining other downstream aberrations in the tumorigenesis of solitary fibrous tumours appear promising for individual molecular identification. ${ }^{729}$

In this study, two of three bladder solitary fibrous tumours (cases 7 and 8) had malignant features and large tumour size, yet showed no recurrence after 60 months and 132 months. The few published cases of bladder solitary fibrous tumours $(n=17)$ reported both malignant and bland histological features, yet no recurrence. These reports did not examine NAB2-STAT6 gene fusion presence or STAT6 nuclear expression. The third case in this study (case 9) showed a rapid recurrence after 12 months. This behaviour may relate to proposed mechanistic pathways for development of a malignant solitary fibrous tumour involving dedifferentiation of a pre-existing benign tumour and acquisition of additional complex genetic aberrations. ${ }^{32} 33$ As in other sites, studies are currently expanding the understanding of other genes overexpressed in solitary fibrous tumours, which may lead to insight into the mechanisms of progression and insight into subsequent therapeutic targets. ${ }^{9}$ 32-34

In this study, the lack of agreement between STAT6 immunohistochemical staining and NAB2-STAT6 fusion expression by FISH reflects the extensive distribution of break points at the transcript levels that require several primers for complete analysis. ${ }^{29}$ As published, all fusion transcripts contain the first two
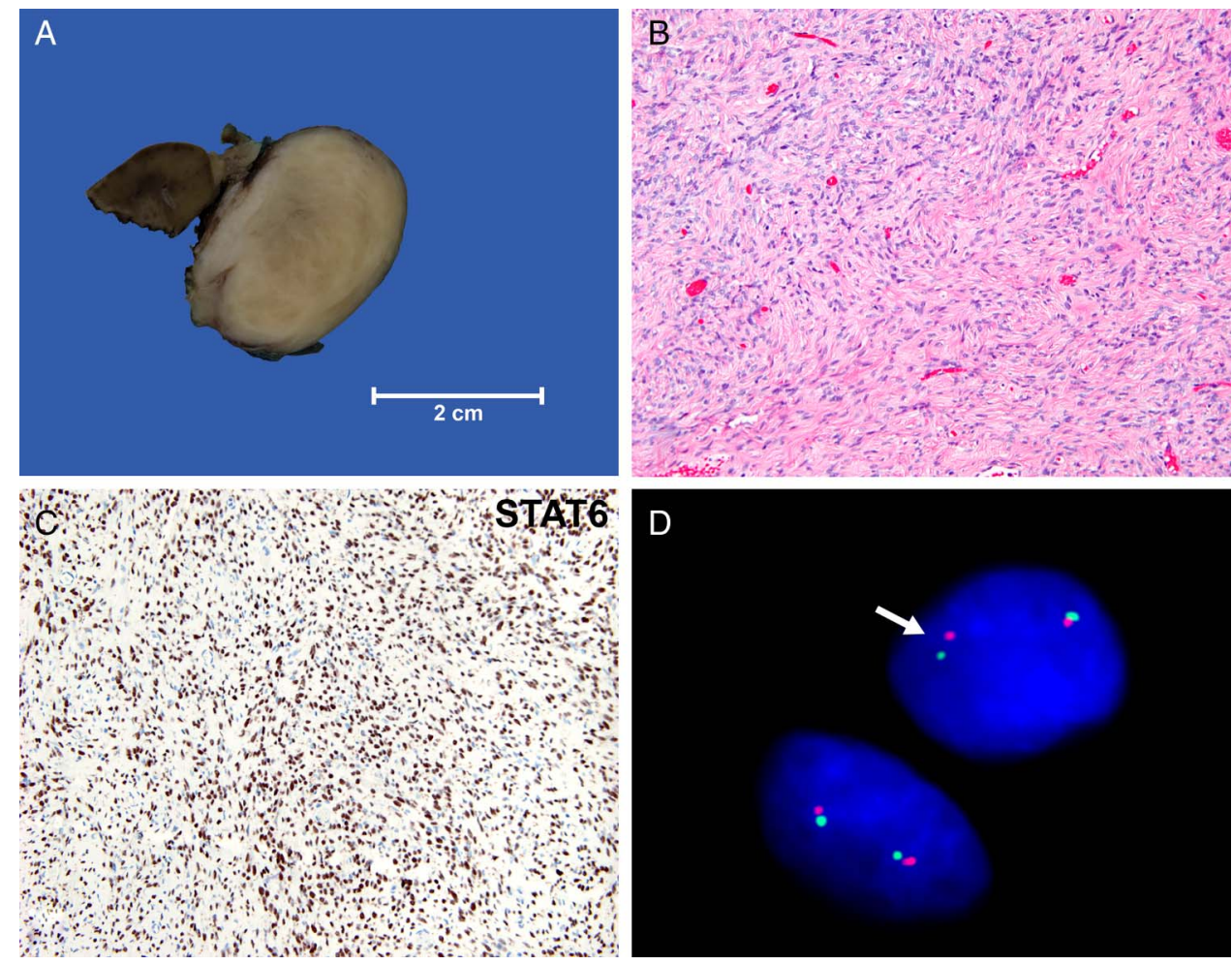

Figure 2 Solitary fibrous tumours of the genitourinary tract. (A) Typical solitary fibrous tumour gross appearance showing circumscribed, firm, homogenous white-to-tan mass. In this case, the solitary fibrous tumour is arising from a kidney (upper left aspect of image). (B) Typical solitary fibrous tumour morphology with haphazardly arranged spindle cells set in a hyalinised background with multiple small, branching blood vessels; (C) Nuclear expression of STAT6 seen on immunohistochemical staining (200x); (D) Fluorescence in situ hybridisation (FISH) analysis showing break apart of the STAT6 (green) and its upstream sequence (orange) suggesting the fusion between NAB2 and STAT6. 

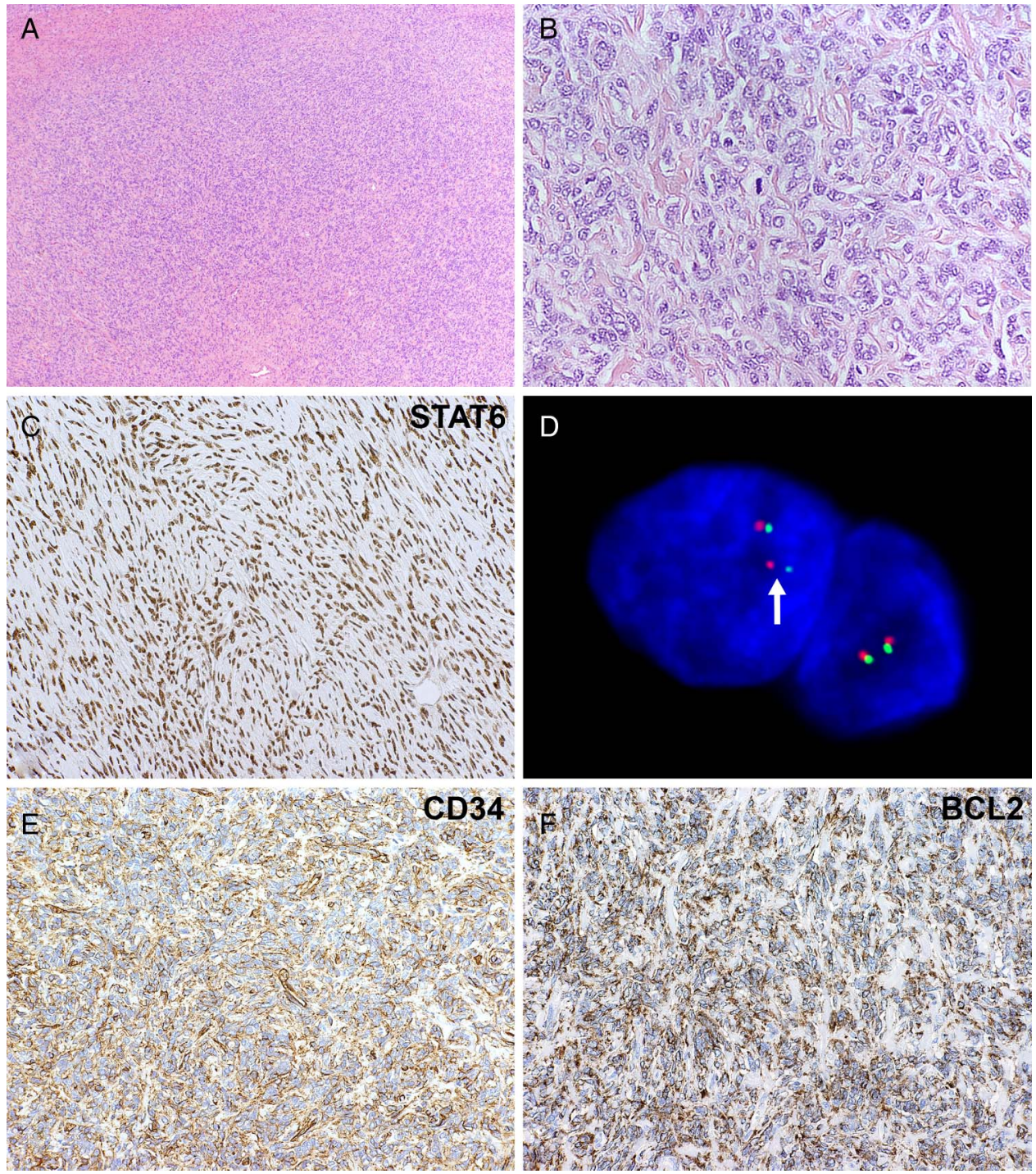

Figure 3 Aggressive solitary fibrous tumour of the genitourinary tract (case 1). (A and B) Solitary fibrous tumour showing aggressive features $(100 x$ and $200 x$, respectively). The tumour shows moderate degree of cellularity with cells adjacent to each other and limited sclerotic collagen bands. There is moderate pleomorphism with nucleoli readily visible. A mitotic figure is displayed in the centre of (B); (C) Nuclear expression of STAT6 seen on immunohistochemical staining (200x); (D) Fluorescence in situ hybridisation (FISH) analysis showing break apart of the STAT6 (green) its upstream (orange) signals suggesting NAB2-STAT6 fusion; (E and F) Cytoplasmic expression of CD34 and bcl-2, respectively (200x).

exons of NAB2 and last six exons of STAT6. However, a range of fusions exist between NAB2 exon4 and STAT6 exon3 and between NAB2 exon 6 and STAT6 exon 17. Moreover, differential expression of the $5^{\prime}$ part of NAB2 can occur, suggesting that some solitary fibrous tumours might have fusion transcripts that require other primers. ${ }^{5} 29$ The lack of agreement between STAT6 immunohistochemical staining and NAB2-STAT6 fusion expression found in this study may result from unique fusions which still translocate the $N A B 2$ to the nucleus and modulate STAT6 gene expression (negative NAB2-STAT6 fusion presence with positive nuclear expression of STAT6). ${ }^{6}{ }^{29}$ In fact, investigators have suggested a prognostic relationship between different fusion variants and the behaviour of solitary fibrous tumours. For example, one study found that detected fusion variants related to particular anatomical subsites of extrathoracic solitary fibrous tumours. ${ }^{22}$ Relationships were also examined between NAB2-STAT6 gene fusion variants, body site location, age and tumour size, and clinical outcomes of solitary fibrous tumours. Although the study did not demonstrate significant relationships, it highlights the potential use of fusion variants for outcome prediction. ${ }^{22}$ STAT6 immunohistochemistry probably suffices for diagnostic evaluation of solitary fibrous tumours. Additional studies such as ours have also shown that the NAB2-STAT6 inversion is not consistently detected by FISH due to very close proximity of the two genes (overlapping ends) and in this setting Reverse transcriptase (RT)-PCR is the preferred method of detection.

Unfortunately, the present study was not designed to examine the presence and relationships of individual gene fusion variants and additional studies are needed. Other limitations of this study are the limited number of subjects in the cohort (inherent in studies of rare entities). As with any retrospective study there is also the potential for selection bias, recall bias and potential impact of unknown confounders. In this study, the effects of selection and analytical bias were minimised by the blinded method of tissue selection, blinded FISH and immunohistochemical analyses, and sequential batch analysis method. The effect of recall bias and confounding variables were minimised in the current study through centralised specimen procurement, reporting and subsequent clinical follow-up. 
Our findings suggest that a subset of solitary fibrous tumours of the genitourinary tract may behave aggressively. Using a break-apart FISH probe cocktail, we found the NAB2-STAT6 gene fusion in $64 \%$ of cases. However, the NAB2-STAT6 fusion status was not correlated with STAT6 expression or useful in discriminating between low-risk or high-risk tumours and subsequent clinical outcomes.

\section{Take home messages}

- Solitary fibrous tumour is a rare lesion in the genitourinary tract. The diagnosis and prognosis can be challenging as it is one of a number of spindle cell lesions which share overlapping immunohistochemical and morphological profiles.

- Genitourinary tract solitary fibrous tumour can be characterised by immunohistochemical stains for the defining fusion partner product STAT6.

- A subset of solitary fibrous tumours of the genitourinary tract tends to be clinically aggressive.

- Using a new break-apart fluorescence in situ hybridisation probe cocktail, we found the NAB2-STAT6 gene fusion in $64 \%$ of cases. However, the NAB2-STAT6 fusion status was not correlated with STAT6 expression or useful in discriminating between low-risk or high-risk tumours and subsequent clinical outcomes.

\section{Author affiliations}

${ }^{1}$ Department of Pathology and Laboratory Medicine, Indiana University School of Medicine, Indianapolis, Indiana, USA

${ }^{2}$ Department of Urology, Indiana University School of Medicine, Indianapolis, Indiana, USA

${ }^{3}$ Department of Pathology and Laboratory Medicine, Henry Ford Health System, Detroit, Michigan, USA

${ }^{4}$ Departments of Pathology and Laboratory Medicine, Case Western Reserve University, Cleveland, Ohio, USA

${ }^{5}$ Department of Pathological Anatomy and Histopathology, School of Medicine, Polytechnic University of the Marche Region (Ancona), Ancona, Italy

${ }^{6}$ Unit of Anatomical Pathology, Department of Surgery, Faculty of Medicine, Cordoba, Spain

${ }^{7}$ Champalimaud Clinical Center, Lisbon, Portugal

${ }^{8}$ Department of Pathology, Emory University School of Medicine, Atlanta, Georgia, USA

${ }^{9}$ Michigan Center for Translational Pathology, University of Michigan, Ann Arbor, Michigan, USA

${ }^{10}$ Department of Pathology and Laboratory Medicine, Dartmouth-Hitchcock Medical Center, Geisel School of Medicine at Dartmouth, Hanover, New Hampshire, USA

Handling editor Cheok Soon Lee

Contributors All authors have contributed to the design and execution of the study.

Competing interests None declared.

Provenance and peer review Not commissioned; externally peer reviewed.

\section{REFERENCES}

1 Galosi AB, Mazzucchelli R, Scarpelli M, et al. Solitary fibrous tumour of the prostate identified on needle biopsy. Eur Urol 2009;56:564-7.

2 Thway K, Ng W, Noujaim J, et al. The current status of solitary fibrous tumor: diagnostic features, variants, and genetics. Int I Surg Pathol 2016;24:281-92.

3 Vogels RJ, Vlenterie M, Versleijen-Jonkers YM, et al. Solitary fibrous tumorclinicopathologic, immunohistochemical and molecular analysis of 28 cases. Diagn Pathol 2014:9:224

4 Gold JS, Antonescu CR, Hajdu C, et al. Clinicopathologic correlates of solitary fibrous tumors. Cancer 2002;94:1057-68.

5 Robinson DR, Wu YM, Kalyana-Sundaram S, et al. Identification of recurrent NAB2-STAT6 gene fusions in solitary fibrous tumor by integrative sequencing. Nat Genet 2013:45:180-5.
6 Chmielecki J, Crago AM, Rosenberg M, et al. Whole-exome sequencing identifies a recurrent NAB2-STAT6 fusion in solitary fibrous tumors. Nat Genet 2013;45:131-2.

7 Akaike K, Kurisaki-Arakawa A, Hara K, et al. Distinct clinicopathological features of NAB2-STAT6 fusion gene variants in solitary fibrous tumor with emphasis on the acquisition of highly malignant potential. Hum Pathol 2015;46:347-56.

8 Tai HC, Chuang IC, Chen TC, et al. NAB2-STAT6 fusion types account for clinicopathological variations in solitary fibrous tumors. Mod Pathol 2015;28:1324-35.

9 Bertucci F, Bouvier-Labit C, Finetti P, et al. Gene expression profiling of solitary fibrous tumors. PLOS ONE 2013;8:e64497.

10 Demicco EG, Park MS, Araujo DM, et al. Solitary fibrous tumor: a clinicopathological study of 110 cases and proposed risk assessment model. Mod Pathol 2012;25:1298-306.

11 DeVito N, Henderson E, Han G, et al. Clinical characteristics and outcomes for Solitary Fibrous Tumor (SFT): a single center experience. PLOS ONE 2015;10:e0140362.

12 Kao YC, Lin PC, Yen SL, et al. Clinicopathological and genetic heterogeneity of the head and neck solitary fibrous tumours: a comparative histological, immunohistochemical and molecular study of 36 cases. Histopathology 2016;68:492-501.

13 Demicco EG, Harms PW, Patel RM, et al. Extensive survey of STAT6 expression in a large series of mesenchymal tumors. Am J Clin Pathol 2015;143:672-82.

14 Doyle LA, Fletcher CD. Predicting behavior of solitary fibrous tumor: are we getting closer to more accurate risk assessment? Ann Surg Oncol 2013;20:4055-6.

15 Fletcher CDM, Bridge JA, Hogendoorn P, et al. WHO classification of tumors of soft tissue and bone. LARC Press 2013.

16 Doyle LA, Vivero M, Fletcher CD, et al. Nuclear expression of STAT6 distinguishes solitary fibrous tumor from histologic mimics. Mod Pathol 2014;27:390-5.

17 Wang L, Williamson SR, Zhang S, et al. Increased androgen receptor gene copy number is associated with TMPRSS2-ERG rearrangement in prostatic small cell carcinoma. Mol Carcinog 2015;54:900-7.

18 Williamson SR, Zhang S, Yao JL, et al. ERG-TMPRSS2 rearrangement is shared by concurrent prostatic adenocarcinoma and prostatic small cell carcinoma and absent in small cell carcinoma of the urinary bladder: evidence supporting monoclonal origin. Mod Pathol 2011;24:1120-7.

19 Yi ES, Boland JM, Maleszewski JJ, et al. Correlation of IHC and FISH for ALK gene rearrangement in non-small cell lung carcinoma: IHC score algorithm for FISH. J Thorac Oncol 2011;6:459-65.

20 Shaw AT, Yeap BY, Mino-Kenudson M, et al. Clinical features and outcome of patients with non-small-cell lung cancer who harbor EML4-ALK. J Clin Oncol 2009;27:4247-53.

21 Camidge DR, Kono SA, Flacco A, et al. Optimizing the detection of lung cancer patients harboring anaplastic lymphoma kinase (ALK) gene rearrangements potentially suitable for ALK inhibitor treatment. Clin Cancer Res 2010;16:5581-90.

22 Chuang IC, Liao KC, Huang HY, et al. NAB2-STAT6 gene fusion and STAT6 immunoexpression in extrathoracic solitary fibrous tumors: the association between fusion variants and locations. Pathol Int 2016;66:288-96.

23 Herawi M, Epstein Jl. Solitary fibrous tumor on needle biopsy and transurethral resection of the prostate: a clinicopathologic study of 13 cases. Am J Surg Pathol 2007:31:870-6.

24 Guner G, Bishop JA, Bezerra SM, et al. The Utility of STAT6 and ALDH1 expression in the differential diagnosis of solitary fibrous tumor vs prostate specific stromal neoplasms. Hum Pathol 2016;54:184-8.

25 Yang W, Sun F, Liu H, et al. Solitary fibrous tumors of the prostate: a case report. Oncol Lett 2015;10:1617-19.

26 Kuroda N, Ohe C, Sakaida N, et al. Solitary fibrous tumor of the kidney with focus on clinical and pathobiological aspects. Int I Clin Exp Pathol 2014;7:2737-42.

27 Khater N, Khauli R, Shahait M, et al. Solitary fibrous tumors of the kidneys: presentation, evaluation, and treatment. Urol Int 2013;91:373-83.

28 Hsieh TY, ChangChien YC, Chen WH, et al. De novo malignant solitary fibrous tumor of the kidney. Diagn Pathol 2011;6:96.

29 Mohajeri A, Tayebwa J, Collin A, et al. Comprehensive genetic analysis identifies a pathognomonic NAB2/STAT6 fusion gene, nonrandom secondary genomic imbalances, and a characteristic gene expression profile in solitary fibrous tumor. Genes Chromosomes Cancer 2013;52:873-86.

30 Dagrada GP, Spagnuolo RD, Mauro V, et al. Solitary fibrous tumors: loss of chimeric protein expression and genomic instability mark dedifferentiation. Mod Pathol 2015;28:1074-83.

31 Barthelmeß S, Geddert H, Boltze C, et al. Solitary fibrous tumors/ hemangiopericytomas with different variants of the NAB2-STAT6 gene fusion are characterized by specific histomorphology and distinct clinicopathological features. Am J Pathol 2014;184:1209-18.

32 Dozier J, Jameel Z, McCain DA, et al. Massive malignant solitary fibrous tumor arising from the bladder serosa: a case report. J Med Case Rep 2015;9:46.

33 Spairani C, Squillaci S, Pitino A, et al. A case of concomitant occurrence of solitary fibrous tumor and urothelial high-grade invasive carcinoma of the urinary bladder. Int I Surg Pathol 2014;22:252-9.

34 Prévot S, Penna C, Imbert JC, et al. Solitary fibrous tumor of the adrenal gland. Mod Pathol 1996:9:1170-4. 


\section{$\mathrm{JCP}$}

Solitary fibrous tumour of the genitourinary tract: a clinicopathological study of 11 cases and their association with the NAB2-STAT6 fusion gene

Erik Kouba, Novae B Simper, Shaoxiong Chen, Sean R Williamson, David J Grignon, John N Eble, Gregory T MacLennan, Rodolfo Montironi, Antonio Lopez-Beltran, Adeboye O Osunkoya, Shaobo Zhang, Mingsheng Wang, Lisha Wang, Thu Tran, Robert E Emerson, Lee Ann Baldrige, M Francesca Monn, Konstantinos Linos and Liang Cheng

J Clin Pathol published online October 31, 2016

Updated information and services can be found at:

http://jcp.bmj.com/content/early/2016/10/31/jclinpath-2016-204088

These include:

References This article cites 33 articles, 5 of which you can access for free at: http://jcp.bmj.com/content/early/2016/10/31/jclinpath-2016-204088 \#BIBL

Email alerting Receive free email alerts when new articles cite this article. Sign up in the service box at the top right corner of the online article.

Topic Articles on similar topics can be found in the following collections Collections Molecular genetics (353)

\section{Notes}

To request permissions go to:

http://group.bmj.com/group/rights-licensing/permissions

To order reprints go to:

http://journals.bmj.com/cgi/reprintform

To subscribe to BMJ go to:

http://group.bmj.com/subscribe/ 